\title{
A Case Report of Bizarre Generalized Gingival Hyperplasia with Supernumerary Teeth Mimicking Zimmermann-Laband Syndrome
}

\author{
Dr. Khizer Hussain Afroze $\mathrm{M}^{1}$, Dr. Adeeb Thaha $\mathrm{C} \mathrm{S}^{2^{*}}$, Dr. Farha Aysha K T
}

\author{
${ }^{1}$ Assistant Professor, Department of Anatomy, MVJ Medical College \& Research Hospital, Hoskote, Bangalore India \\ ${ }^{2}$ Consultant Periodontist, Asian Dental Care, Bangalore India \\ ${ }^{3}$ Dental Surgeon, Asian Dental Care, Bangalore India
}

\begin{abstract}
DOI: $10.36348 /$ SIJAP.2019.v02i10.006
| Received: 11.10.2019 | Accepted: 18.10.2019 | Published: 27.10.2019
\end{abstract}

*Corresponding author: Dr. Adeeb Thaha CS

\section{Abstract}

Gingival hyperplasia or enlargement is usually a secondary manifestation of underlying systemic diseases or drug induced or part of a syndrome. In certain cases if the causative factors of gingival enlargement are unknown, then it should be categorized as idiopathic gingival hyperplasia. We are presenting a case report of idiopathic gingival hyperplasia with the chief complaints of generalized gingival hyperplasia with supernumerary teeth mimicking Zimmermann Laband syndrome. The management of patients with idiopathic gingival hyperplasia should be thoroughly examined to rule out the known cause and blood samples should be taken to exclude blood dyscrasias.

Keywords: Gingival hyperplasia, Gingival enlargement, Zimmermann-Laband Syndrome, Supernumerary teeth.

Copyright @ 2019: This is an open-access article distributed under the terms of the Creative Commons Attribution license which permits unrestricted use, distribution, and reproduction in any medium for non-commercial use (NonCommercial, or CC-BY-NC) provided the original author and source are credited.

\section{INTRODUCTION}

Gingivitis is referred to as an inflammatory reaction of the gingiva caused by the bacterial plaque colonization on tooth surfaces and subsequent invasion of microorganisms into the gingival sulcus[1]. Gingival hyperplasia or enlargement is usually a secondary manifestation of underlying systemic diseases such as thyroid, pregnancy, diabetes or puberty[2]. It may be due to adverse effects of conception of certain drugs like calcium channel blockers, immunosuppressants, and anticonvulsants[3]. The blood-related disorders like acute monocytic, lymphocytic or myelocytic leukemia are highly associated with gingival enlargement[2]. Gingival enlargement or hyperplasia is associated with many known syndromes such as Zimmermann- Laband syndrome, Rutherford's syndrome (corneal dystrophy), Cross syndrome, and Ramon's syndrome [4, 5]. In certain cases the causative factors of gingival enlargement are unknown, then it should be categorized as idiopathic gingival hyperplasia. We are presenting a case report of idiopathic gingival hyperplasia with the chief complaints of generalized gingival hyperplasia with supernumerary teeth mimicking Zimmermann Laband syndrome.

\section{CASE REPORT}

A boy aged about 12 years born to a consanguineous couple referred from the Department of pedodontics, KLE Dental College \& Hospital, Bangalore, India, with the complaints of gradual and progressive enlargement of upper gingival tissue since 1 year and forwardly placed upper front teeth since 2 years. A detailed history was taken. His mother's obstetric history revealed uncomplicated pregnancy with no history of diabetes or hypertension and her age at conception was 23 years. His father's history was non-contributory. He has an elder male sibling aged about 14 years presenting with similar swelling noticed for 6 months.

On extraoral examination of the patient revealed the facial asymmetry, dolichocephalic head with convex profile and incompetent protruded lips. Orbital Hypertelorism (abnormally increased distance between the orbits) was seen. The upper limb examination revealed the presence of polydactyly in left hand (Figure1). 


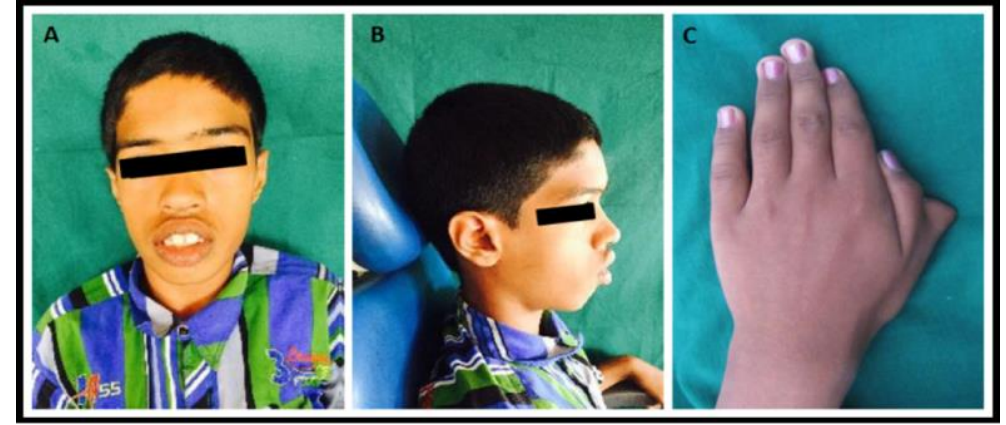

Fig-1: shows A) Facial asymmetry, Dolichocephalic head with convex profile B) Protruded lips, C) polydactyly in the left hand

On intraoral examination, the patient presented with marked generalized upper gingival hyperplasia with a high arched palate. Gingival tissue was pale pink in colour with firm and resilient consistency. The loss of contour in gingival tissue was also noted (Figure 2). Gingival tissue illustrates minimal bleeding on probing and did not show any release of exudates. Papilla penetrating type frenum was seen. On occlusal analysis, patient had a class II canine relation with prognathic maxilla along with generalized spacing, increased overjet and deep bite (Figure 3).

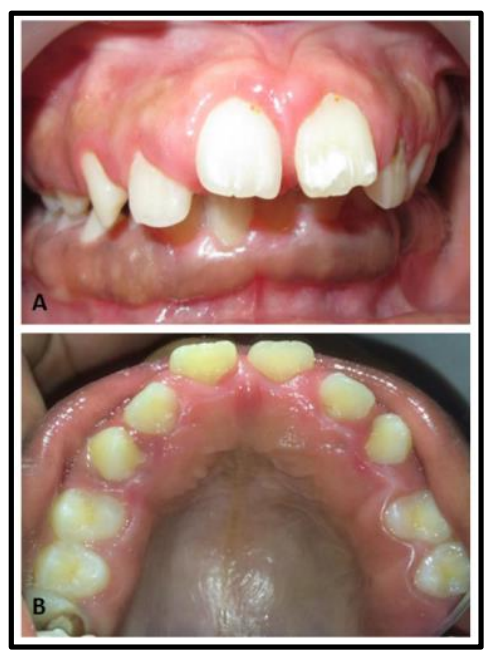

Fig-2: Shows A) Generalized gingival hyperplasia B) High arched Palate

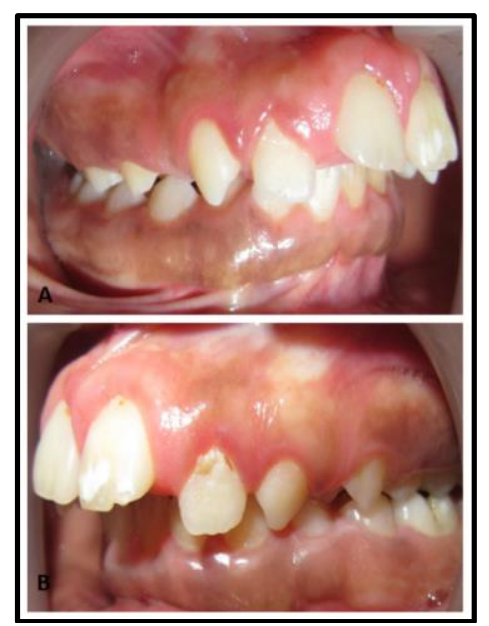

Fig-3: Right \& Left lateral view shows prognathic Maxilla with spacing
Presence of 6 supernumerary teeth $S_{1}(13,14)$; $\mathrm{S}_{2}(15,16) ; \mathrm{S}_{3}(22,23) ; \mathrm{S}_{4}(24,25) ; \mathrm{S}_{5}(42,43) ; \mathrm{S}_{6}(43,44)$ was exhibited by using Orthopantomagram (Figure 4). Hematological analysis revealed that all the parameters were within physiological limits. Genetic karyotyping shows normal.

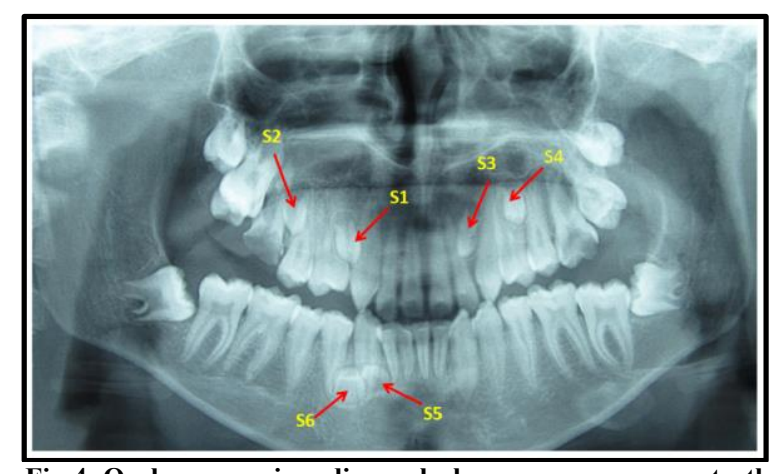

Fig-4: Oral panoramic radiograph shows supernumerary teeth

\section{DISCUSSION}

In the literature review, we come across many possible potential theories that can cause or influence the hyperplasia of gingiva. Gingival enlargement is influenced by various factors such as plaque and few systemic factors like changes in hormonal levels, consumption of certain drugs and hereditary[6]. Gingival enlargement or hyperplasia is associated with many known syndromes such as Zimmermann-Laband syndrome, Rutherford's syndrome (corneal dystrophy), Cross syndrome, and Ramon's syndrome. The first two syndromes are autosomal dominant and rest are autosomal recessive genetic disorder [4, 5]. A syndrome has been reported by Wynne et al. and Takagi et al. which is associated with hearing deficiencies, hypertelorism and supernumerary teeth $[7,8]$.

Zimmermann et al. in 1928 were the first who described the two cases characterized by gingival fibromatosis associated with abnormalities of the nose and ears, absence or hyperplasia of the nails or terminal phalanges of the hands and feet. Then in 1964, a family revealed the gingival fibromatosis associated with splenomegaly, skeletal and soft tissue abnormalities which were described by Laband. Later above said condition was coined as Zimmermann- Laband syndrome [9]. 
The present case mimics Zimmermann-Laband syndrome with the presenting complaints of generalized gingival enlargement along with forwardly placed upper front teeth. Patients also elicited the clinical features like facial asymmetry, dolichocephalic head, Orbital hypertelorism, and polydactyly in left hand and presence of supernumerary teeth. The patient was referred to karyotyping and genetic counseling. H/O congenital malformation in other offspring and members of their family and parental consanguinity was noted. Zimmermann-Laband syndrome was confirmed based on signs, physical examination, and clinical features but karyotyping results show the negative for above said condition.

The clinical features and physical examination of the present case did not fit into any other syndromes. Hence we postulated this type of gingival enlargement should be categorize as idiopathic gingival hyperplasia. Patil L et al. reported a case of idiopathic gingival hyperplasia [2].

Patients with gingival hyperplasia should be thoroughly examined and blood samples should be taken to exclude blood dyscrasias. Hematological investigations of our patient were within the physiological limits. The treatment of any syndrome associated with gingival hyperplasia is patient specific which is directed towards their symptoms. Specific therapies are symptomatic and supportive. Early intervention is very important so as to ensure that children reach their potential. Genetic counseling should be carried out for affected individuals and their families. As the syndromic patients suffer from other systemic conditions, routine general evaluation and follow up is of utmost importance.

In our patient, the treatment plan was as follows; education and motivation of the patient regarding oral hygiene maintenance, oral prophylaxis and surgical management of gingival hyperplasia performing gingivectomy procedures. Extraction of supernumerary teeth under general anesthesia following which fixed orthodontic therapy. The patient is currently under treatment and follows up.

\section{CONCLUSION}

The treatment of any syndrome associated with gingival hyperplasia is patient specific which is directed towards their symptoms. Multidisciplinary approach should be undertaken by Department of Pedodontics, Periodontics and Orthodontics in evaluating the patient. The management of patients with idiopathic gingival hyperplasia should be thoroughly examined to rule out the known cause and blood samples should be taken to exclude blood dyscrasias. In the present case, the treatment plan includes gingivectomy, extraction of supernumerary teeth, followed by orthodontic treatment.

\section{REFERENCES}

1. Shafer, W. G., Hine, M. K., Levy, B. M., Rajendran, R., \& Sivapathasundharam, B. (1983). A textbook of oral pathology. Philadelphia: Saunders. 786.

2. Patil, L., Shah, P., Chopade, P., Patil, S., \& Bangar, C. (2016). Idiopathic Gingival Hyperplasia: a case report. Journal of International Medicine and Dentistry, 3(1), 52-57.

3. Camargo, P. M., Melnick, P. R., Pirih, F. Q., Lagos, R., \& Takei, H. H. (2001). Treatment of drug-induced gingival enlargement: aesthetic and functional considerations. Periodontology 2000, 27(1), 131-138.

4. Holzhausen, M., Ribeiro, F. S., Gonçalves, D., Corrêa, F. O. B., Spolidorio, L. C., \& Orrico, S. R. P. (2005). Treatment of gingival fibromatosis associated with Zimmermann-Laband syndrome. Journal of periodontology, 76(9), 15591562.

5. Gorlin, R. J., Cohen Jr, M. M., \& Hennekam, R. C. (2001). Syndromes of the head and neck. Oxford University Press.

6. Arora, N., Vizo, K., Bharti., V.(2016). A Case Report of Idiopathic Gingival Enlargement with Tooth Repositioning after Surgical Therapy. Int J Oral Health Med Res, 3(4):72-4.

7. Wynne, S. E., Aldred, M. J., \& Bartold, P. M. (1995). Hereditary gingival fibromatosis associated with hearing loss and supernumerary teeth - a new syndrome. Journal of periodontology, 66(1), 75-79.

8. Takagi, M., Yamamoto, H., Mega, H., Hsieh, K. J., Shioda, S., \& Enomoto, S. (1991). Heterogeneity in the gingival fibromatoses. Cancer, 68(10), 22022212.

9. Bazopoulou-Kyrkanidou, E., Papagianoulis, L., Papanicolaou, S., \& Mavrou, A. (1990). Laband syndrome: a case report. Journal of Oral Pathology \& Medicine, 19(8), 385-387. 